\title{
Glucose Testing and Lifestyle Counseling of Obese and Overweight Patients: A Survey of Primary Care Physicians in the United States
}

\author{
Casagrande $\mathrm{S}^{*}$, Cowie $\mathrm{CC}^{2}$, Yanovski $\mathrm{SZ}^{2}$, Smith $\mathrm{AW}^{3}$, Ballard $\mathrm{R}^{3}$, Lee $\mathrm{R}^{4}$ and Staten $\mathrm{M}^{2}$ \\ ${ }^{1}$ Social \& Scientific Systems, Inc., Silver Spring, Maryland, USA \\ ${ }^{2}$ National Institute of Diabetes and Digestive and Kidney Diseases, Bethesda, Maryland, USA \\ ${ }^{3}$ National Cancer Institute, Medical Center Drive, Bethesda, Maryland, USA \\ ${ }^{4}$ Information Management Services, Inc., Calverton, Maryland, USA
}

*Corresponding author: Casagrande S, PhD, Social \& Scientific Systems, Inc., 8757 Georgia Ave, Silver Spring, Maryland, USA 20910, E-mail: scasagrande@s-3.com

Citation: Casagrande S, Cowie CC, Yanovski SZ, Smith AW, Ballard R, et al. (2015) Glucose Testing and Lifestyle Counseling of Obese and Overweight Patients: A Survey of Primary Care Physicians in the United States. J Obes Overweig 1(2): 203. doi: 10.15744/2455-7633.1.203

Received Date: June 02, 2015 Accepted Date: August 24, 2015 Published Date: August 26, 2015

\begin{abstract}
Background: Few national data exist on glucose testing or providing lifestyle advice to patients with or at risk for diabetes by primary care physicians (PCPs).

Objective: To determine the frequency of glucose testing in overweight and obese patients and the prevalence of lifestyle counseling by PCPs for patients with or at risk for diabetes.

Methods: A nationally representative survey of 1211 PCPs sampled from the American Medical Association's Masterfile in 2008. Outcomes included frequency of random or fasting blood glucose (FBG) testing, provision of advice on physical activity, weight control, or diet, and the effect of incentive payments on glucose testing.

Results: More physicians reported utilizing FBG testing compared to random blood glucose testing among overweight/obese patients with additional risk factors for chronic diseases $(92.7 \%$ vs. $75.0 \%, p<0.001)$. In addition, the prevalence of testing FBG $\geq 1$ time per year was reported more often for internal medicine and family physicians vs. obstetricians/gynecologists, and by non-Hispanic Asian vs. non-Hispanic white physicians $(\mathrm{p} \leq 0.001)$. For physicians who treat patients with diabetes or a family history of diabetes, the prevalence of addressing diet, physical activity or weight control was high $(>90 \%)$. Although most PCPs reported not receiving incentive payments for diabetes screening (83.5\%), those that did more often reported testing glucose $\geq 1$ time per year $(\mathrm{p}<0.001)$.

Conclusion: PCPs are testing FBG more regularly than random glucose. The majority of PCPs are testing FBG at least annually in their overweight and obese patients but few receive any additional financial incentive.

Keywords: Diabetes; Screening; Fasting blood glucose test; Physician practices; Screening practices

Abbreviations: ADA: American Diabetes Association; FBG: Fasting blood glucose; FPG: Fasting plasma glucose; HbA1c: Hemoglobin A1c; OB/GYN: Obstetrics and Gynecology; OGTT: Oral glucose tolerance test; PCPs: Primary care providers; RBG: Random blood glucose
\end{abstract}

\section{Introduction}

In the United States (U.S.), the costs for health care and lost productivity due to diagnosed diabetes has increased from $\$ 174$ billion in 2007 to $\$ 245$ billion in 2012, making it one of the fastest growing public health burdens [1]. Nearly 26 million adults have diabetes, and another 79 million have prediabetes, a condition that increases the risk for developing type 2 diabetes [2]. Clearly to reduce the costs and improve health, preventing diabetes must be a priority. The Diabetes Prevention Program study showed that a lifestyle modification program of reduced dietary intake and increased physical activity resulting in a $7 \%$ weight loss can delay or prevent progression to type 2 diabetes in overweight and obese adults at high risk by more than $50 \%$ [3]. Thus, focusing on methods to address overweight, improve diet and increase physical activity is essential.

More than one-third of adults in the U.S. are obese, defined as a BMI greater than or equal to $30 \mathrm{~kg} / \mathrm{m}^{2}$. Obesity is accompanied by increased risk for type 2 diabetes as well as greater levels of hypertension, dyslipidemia and risk for cardiovascular disease [4]. The incidence of obesity increased over the past 3 decades, although rates appear to be stabilizing for most groups over the last decade [5]. As recommended by the U.S. Preventive Services Task Force, it is imperative that primary care physicians (PCPs) screen their patients for obesity, and offer or refer their obese patients for high-intensity lifestyle interventions [6]. It is well recognized that health care providers can impact their patients' perception of their need to lose weight and advice from a physician has in some cases been reported to result in increased physical activity and weight loss [6-10]. Although low-intensity counseling by PCPs generally has limited effectiveness, working with patients to determine weight loss and health goals is an important first step in encouraging weight control $[11,12]$. 
Few data are available on the extent to which PCPs are assessing diet and physical activity in their patients and providing lifestyle advice. The National Cancer Institute (NCI) of the National Institutes of Health developed the National Survey of Energy Balance Related Care among Primary Care Physicians (EB-PCP), cosponsored by the Eunice Kennedy Shriver National Institutes of Child Health and Human Development, National Institute of Diabetes and Digestives and Kidney Diseases, the NIH Office of Behavioral and Social Sciences Research, and the Centers for Disease Control [13]. This nationally representative survey targeted four primary care specialties and included specific questions regarding glucose testing and lifestyle counseling. The American Diabetes Association recommends that all overweight or obese persons with additional risk factors, including physical inactivity, family history, high-risk race/ethnicity, women with a previous diagnosis of gestational diabetes or polycystic ovary syndrome, hypertension, poor cholesterol levels, prediabetes, or a history of cardiovascular disease, be tested for diabetes; in addition, all persons age $\geq 45$ years should be tested [14]. The purpose of the current study is to determine the frequency of blood glucose testing by PCPs for patients who are overweight or obese and the frequency of testing by practice and physician characteristics. In addition, the prevalence of addressing diet, physical activity, and weight control among patients with diabetes or family history of diabetes is assessed and compared to the prevalence of lifestyle advice given to those with unhealthy behaviors but without weight-related chronic disease.

\section{Methods}

The sampling methodology for the EB-PCP survey has been described elsewhere [13]. Briefly, a systematic stratified sample of PCPs was obtained using the American Medical Association's (AMA) Physician Masterfile as the sampling frame and data was collected between March and December 2008. The Masterfile includes demographic and practice-related data on all allopathic and most osteopathic physicians in the U.S. A random sample of 4429 physicians was drawn using specialty (family physicians, internists, pediatricians, and obstetricians/gynecologists) as the sampling strata to meet the targeted sample size of at least 400 respondents per PCP specialty. The sampling frame was sorted by U.S. Census region (Northeast, Midwest, South, and West); practice urbanicity; and physician sex to ensure adequate representation of these characteristics. The sample weight within each specialty stratum was proportional to the specialty's representation in the total U.S. physician population; thus, the survey data are nationally representative. The EB-PCP survey included 2,027 PCPs and physicians were in active, non-federal practices treating adults and/or children. The EB-PCP survey included three questionnaires: two versions of a physician questionnaire (tailored for those with adult or child patients) and a questionnaire examining the physician's practice environment that was completed by a subset of physician practices [15]. The current analysis uses data from the adult-focused questionnaire $(\mathrm{n}=1211)$ and the practice environment questionnaire $(n=1034)$. The response rate for completing the physician questionnaire was $64.5 \%$ and the response rate for the practice environment questionnaire was $86 \%$; the response rate was $55.5 \%$ for completing both questionnaires. The Office of Human Subjects Research reviewed the protocol and all related materials and designated the study exempt from IRB review (Exempt \#3827, dated July 31, 2007).

\section{Blood glucose testing}

Physicians responding to the adult patient-focused questionnaire reported on the utilization and frequency of random or FBG testing among overweight or obese patients. First, physicians reported on whether they utilize blood glucose testing with or without the presence of additional risk factors for chronic diseases, for example, dyslipidemia, hypertension, or diabetes. Next, physicians who utilize blood glucose testing reported the frequency of testing by the presence or absence of additional risk factors. Responses for the frequency of testing included every 2 years, annually, every 6 months, more than twice a year, and other.

\section{Nutrition, physical activity, and weight control}

Physicians were asked whether they address the need for improved diet/nutrition, physical activity, or weight control when treating patients who (1) have type 2 diabetes, (2) have a family history of type 2 diabetes, or (3) do not have weight-related chronic disease but have poor lifestyle behaviors or are overweight. For physicians who treat patients with type 2 or a family history of diabetes, physicians were asked "do you address diet/nutrition, physical activity, or weight control?" Responses were dichotomous (noted or not). Physicians who treat adult patients without weight-related chronic disease but who had an unhealthy diet, insufficient physical activity, or who were overweight, were asked whether they provide specific guidance on diet/nutrition, physical activity, or weight control. Responses were categorized as always or often vs. sometimes, rarely or never.

\section{Characteristics of physicians and medical practices}

The American Medical Association's Physicians Masterfile was used to obtain information on physician specialty, years since graduation from medical school, and region and urbanicity. In the practice environment questionnaire, physicians or a proxy (e.g., office staff) reported on physician age, sex, race/ethnicity, the patient population treated, and whether physicians in the practice receive any incentive payments to perform diabetes screening; $85 \%$ of practice environment questionnaires were completed by a physician as opposed to a proxy. 


\section{Statistical Analysis}

Percentages and standard errors were computed to describe the frequency of blood glucose testing and the prevalence of blood glucose testing $\geq 1$ time per year according to physician and practice characteristics; for the prevalence of providing counseling or specific guidance for diet, physical activity or weight control; and for the prevalence of receiving incentive payments for diabetes screening. Differences in prevalence estimates were tested for statistical significance using two-sided t-tests; $\mathrm{p}$-values were estimated using the test statistic and the degrees of freedom. Survey weights adjusting for oversampling of family physicians, undercoverage and survey nonresponse were applied in all analyses; the weighted data yield national estimates. Standard errors were included which are a measure of the sampling variability in the estimate; the standard errors are a function of the population standard deviation, the sample size, and the study design. Replicate weights were generated for variance estimation using the Jackknife replication method [16]. SAS-callable SUDAAN (version 10.0 Research Triangle Institute, 2008) was used for analysis.

\section{Results}

\section{Frequency of blood glucose testing among adult patients who are overweight or obese}

More physicians reported utilizing FBG testing compared to random blood glucose testing among overweight or obese patients (Table 1); either fasting or random blood glucose testing was performed more often in patients with additional risk factors compared to patients without additional risk factors. Specifically, when asked about overweight or obese patients with additional risk factors, $92.7 \%$ of physicians reported utilizing FBG testing and $75.0 \%$ of physicians reported utilizing random blood glucose testing $(\mathrm{p}<0.001)$. For patients without additional risk factors, FBG testing was reported by $85.7 \%$ of physicians while random blood glucose testing was reported by $70.6 \%$ of physicians $(\mathrm{p}<0.001)$. Utilization of FBG testing for patients with or without additional risk factors was higher in men vs. women ( $94.5 \%$ vs. $89.5 \%, \mathrm{p}<0.001$ and $87.9 \%$ vs. $81.8 \%, \mathrm{p}=0.003$, respectively); utilization of random blood glucose testing for patients without additional risk factors was greater for men vs. women ( $\mathrm{p}=0.008$ ). FBG testing every 6 months, or more than twice a year, was more frequent for overweight or obese patients with additional risk factors (45.3\%) compared to those without additional risk factors (13.4\%, $\mathrm{p}<0.001)$. Finally, the prevalence of testing FBG $\geq 1$ time per year was greater for patients with additional risk factors (96.7\%) compared to those without additional risk factors $(80.8 \%$, $\mathrm{p}<0.001$ ) (Table1 and 2).

\begin{tabular}{|c|c|c|c|c|c|c|c|c|}
\hline & \multicolumn{4}{|c|}{ Fasting Blood Glucose } & \multicolumn{4}{|c|}{ Random blood glucose } \\
\hline & \multicolumn{2}{|c|}{$\begin{array}{l}\text { With additional risk } \\
\text { factors }\end{array}$} & \multicolumn{2}{|c|}{$\begin{array}{l}\text { Without additional risk } \\
\text { factors }\end{array}$} & \multicolumn{2}{|c|}{$\begin{array}{l}\text { With additional risk } \\
\text { factors }\end{array}$} & \multicolumn{2}{|c|}{$\begin{array}{l}\text { Without additional } \\
\text { risk factors }\end{array}$} \\
\hline & $\mathbf{N}$ & $\%$ (SE) & $\mathbf{N}$ & $\%(\mathrm{SE})$ & $\mathbf{N}$ & $\%(\mathrm{SE})$ & $\mathbf{N}$ & $\%(\mathrm{SE})$ \\
\hline Utilization of Testing & 1,203 & & 1,193 & & 1,195 & & 1,188 & \\
\hline Utilize & & $92.7(0.6)^{\mathrm{a}}$ & & $85.7(0.9)^{\mathrm{b}}$ & & $75.0(1.2)^{\mathrm{a}}$ & & $70.6(1.3)^{\mathrm{b}}$ \\
\hline Do not utilize/not applicable & & $7.3(0.6)$ & & $14.3(0.9)$ & & $25.0(1.2)$ & & $29.4(1.3)$ \\
\hline Frequency ${ }^{*}$ & 985 & & 856 & & 759 & & 693 & \\
\hline Every 2 years & & $3.3(0.5)$ & & $19.2(1.4)$ & & $3.1(0.5)$ & & $19.1(1.5)$ \\
\hline Annually & & $51.4(1.7)$ & & $67.4(1.6)$ & & $50.5(1.9)$ & & $67.2(1.7)$ \\
\hline Every 6 months & & $26.0(1.5)^{c}$ & & $9.8(1.0)^{c}$ & & $28.2(1.8)^{e}$ & & $9.8(1.1)^{\mathrm{e}}$ \\
\hline$>2$ times per year & & $19.3(1.2)^{\mathrm{d}}$ & & $3.6(0.6)^{d}$ & & $18.2(1.3)^{\mathrm{f}}$ & & $3.9(0.7)^{f}$ \\
\hline
\end{tabular}

* Frequency distribution only includes physicians who report utilizing blood glucose testing; For fasting blood glucose with additional risk factors, 985 utilized testing; without risk factors, 856 utilized testing; For random blood glucose with additional risk factors, 759 utilized testing; without additional risk factors, 1,188 utilized testing.

$\mathrm{a}, \mathrm{b}, \mathrm{c}, \mathrm{d}, \mathrm{e}, \mathrm{f} \mathrm{p}<0.001$

The standard error is a measure of the sampling variability in the estimate; it is a function of the population standard deviation, the sample size, and the study design.

Table 1: Frequency of blood glucose testing for patients who are overweight or obese

\section{Prevalence of testing FBG $\geq 1$ time per year by physician characteristics among patients who are over- weight or obese}

Differences by specialty were identified. Internal medicine and family physicians reported testing FBG $\geq 1$ time per year for patients with additional risk factors more often than obstetrician/gynecologists ( $99.2 \%$ and $99.1 \%$ vs. $79.6 \%$, respectively, $\mathrm{p}<0.001$ for both) (Table 2). In addition, the prevalence of FBG testing was reported more often by non-Hispanic Asian physicians compared to non-Hispanic white physicians $(99.1 \%$ vs. $96.1 \%, \mathrm{p}=0.001)$. There was no difference in testing prevalence by practice type, sex of physician, years since physician graduation from medical school, or region of practice. 


\begin{tabular}{|c|c|c|}
\hline & \multicolumn{2}{|c|}{ Percent Testing Fasting Blood Glucose $\geq 1$ Time Per Year ${ }^{*}$} \\
\hline & With additional risk factors $(n=985)$ & Without additional risk factors $(\mathrm{n}=856)$ \\
\hline & $\%(\mathrm{SE})$ & $\%(\mathrm{SE})$ \\
\hline Overall & $96.7(0.5)^{\mathrm{a}}$ & $80.8(1.4)^{\mathrm{a}}$ \\
\hline \multicolumn{3}{|l|}{ Practice type } \\
\hline Solo practice & $96.4(1.1)$ & $86.1(2.3)^{b}$ \\
\hline Group practice & $96.6(0.6)$ & $79.4(2.1)^{\mathrm{b}}$ \\
\hline Medical school & $100.0(0.0)$ & $84.2(16.4)$ \\
\hline Hospital & $98.7(1.3)$ & $81.2(7.1)$ \\
\hline $\begin{array}{c}\text { Clinic or Community } \\
\text { Health Center }\end{array}$ & $97.0(1.7)$ & $76.2(6.8)$ \\
\hline \multicolumn{3}{|l|}{ Primary specialty } \\
\hline Internal Medicine & $99.2(0.5)$ & $90.9(1.6)^{c(\text { ref })}$ \\
\hline Family Practice & $99.1(0.5)$ & $77.4(2.4)^{\mathrm{c}}$ \\
\hline OB/GYN & $79.6(2.5)$ & $54.2(4.0)^{\mathrm{c}}$ \\
\hline \multicolumn{3}{|c|}{ Years since medical school } \\
\hline$\leq 10$ & $96.9(1.1)$ & $77.7(3.7)$ \\
\hline $11-20$ & $97.5(0.7)$ & $80.7(2.4)$ \\
\hline $21-30$ & $96.7(0.9)$ & $80.0(2.4)$ \\
\hline$\geq 31$ & $95.4(1.3)$ & $84.6(2.5)$ \\
\hline \multicolumn{3}{|l|}{ Gender } \\
\hline Male & $96.6(0.6)$ & $80.4(1.7)$ \\
\hline Female & $96.9(0.9)$ & $81.7(2.3)$ \\
\hline \multicolumn{3}{|l|}{ Race/Ethnicity } \\
\hline Non-Hispanic White & $96.1(0.7)^{\mathrm{d}}$ & $78.9(1.7)^{\mathrm{e}}$ \\
\hline Non-Hispanic Black & $98.7(1.3)$ & $92.5(3.9)^{\mathrm{e}}$ \\
\hline Non-Hispanic Asian & $99.1(0.5)^{d}$ & $81.7(3.9)$ \\
\hline Hispanic & $98.2(1.3)$ & $86.6(4.6)$ \\
\hline \multicolumn{3}{|l|}{ Region } \\
\hline Northeast & $98.4(0.7)$ & $84.3(2.7)$ \\
\hline Midwest & $96.7(1.1)$ & $75.7(3.1)$ \\
\hline South & $95.7(0.9)$ & $82.1(2.3)$ \\
\hline West & $96.8(1.0)$ & $81.4(3.0)$ \\
\hline \multicolumn{3}{|l|}{ Practice Urbanicity } \\
\hline Large city & $97.3(0.9)$ & $86.5(2.4)$ \\
\hline Medium city & $93.7(1.5)$ & $82.7(2.9)$ \\
\hline Small city & $97.5(0.8)$ & $78.4(3.0)$ \\
\hline Rural city & $99.3(0.5)$ & $74.0(4.1)$ \\
\hline
\end{tabular}

*Table includes physicians who utilized the screening test as documented in Table 1

${ }^{\mathrm{a}, \mathrm{c}} \mathrm{p}<0.001$

${ }^{\mathrm{e}} \mathrm{p}<0.01$

${ }^{\mathrm{b}} \mathrm{p}<0.05$

The standard error is a measure of the sampling variability in the estimate; it is a function of the population standard deviation, the sample size, and the study design

Table 2: Prevalence of testing FBG $\geq 1$ time/year by physician characteristics for patients who are overweight/obese

When reporting on patients without additional risk factors, more PCPs in solo vs. group practices reported testing FBG $\geq 1$ time per year $(86.1 \%$ vs. $79.4 \%, p=0.033)$. Specialty differences were similar to reports on patients with additional risk factors; more internal medicine (90.9\%) and family practice physicians (77.4\%) reported FBG $\geq 1$ time per year than obstetrician/gynecologists (54.2\%) ( $<0.001$ for both). In addition, non-Hispanic black physicians reported more often testing $F B G \geq 1$ time per year compared to non-Hispanic white physicians $(92.5 \%$ vs. $78.9 \%, \mathrm{p}=0.002)$. 


\section{Prevalence of addressing diet, physical activity and weight control}

For patients with type 2 diabetes, the prevalence of a physician addressing diet, physical activity or weight control was very high (98.9\%, 97.7\%, 94.9\%, respectively) (Table 3). Similarly, about 90\% of physicians addressed each of these behaviors in patients with a family history of type 2 diabetes. The prevalence of addressing diet, physical activity, or weight control for patients with type 2 diabetes or a family history of diabetes was significantly higher compared to patients with unhealthy behaviors or who were overweight but without weight-related chronic disease $(\mathrm{p}<0.05$ for all).

\begin{tabular}{|c|c|c|c|}
\hline & $\begin{array}{c}\text { Patients with type 2 } \\
\text { diabetes }^{\star}(\mathbf{N}=\mathbf{9 6 8})\end{array}$ & $\begin{array}{c}\text { Patients with a family history } \\
\text { of diabetes }^{\mathrm{a}}(\mathbf{N}=\mathbf{1 , 0 4 1})\end{array}$ & $\begin{array}{c}\text { Patients with an unhealthy diet, insufficient activity or over- } \\
\text { weight without weight-related chronic disease }^{\dagger}(\mathbf{N}=\mathbf{1 , 2 0 4})\end{array}$ \\
\hline & $\%$ (SE) & \% (SE) \\
\hline $\begin{array}{c}\text { Provide Counseling/Spe- } \\
\text { cific Guidance On: }\end{array}$ & \multicolumn{2}{|c|}{ Provide General Counseling } & Provide Specific Guidance \\
\hline Diet/Nutrition & $98.9(0.3)^{\mathrm{a}}$ & $90.5(0.9)^{\mathrm{b}}$ & $78.0(1.1)^{\mathrm{a}, \mathrm{b}}$ \\
\hline Physical Activity & $97.7(0.5)^{\mathrm{c}}$ & $90.4(1.0)^{\mathrm{d}}$ & $86.0(1.0)^{\mathrm{c}, \mathrm{d}}$ \\
\hline Weight Control & $94.9(0.7)^{\mathrm{e}}$ & $90.7(1.0)^{\mathrm{f}}$ & $70.3(1.4)^{\mathrm{e}, \mathrm{f}}$ \\
\hline
\end{tabular}

*Estimates are among physicians who treat patients with diabetes or patients with a family history of diabetes

${ }^{\dagger}$ Prevalence includes responses often or always (vs. sometimes, rarely, never) $(13,14)$.

$\mathrm{a}, \mathrm{b}, \mathrm{c}, \mathrm{d}, \mathrm{e}, \mathrm{f} \mathrm{p}<0.05$

The standard error is a measure of the sampling variability in the estimate; it is a function of the population standard deviation, the sample size, and the study design

Table 3: Prevalence of addressing diet, physical activity, and weight control

\section{Prevalence of incentive payments for diabetes screening}

The majority of physicians reported not receiving incentive payments for diabetes screening (83.5\%) compared to a small percentage who did $(13.4 \%, \mathrm{p}<0.001)$ (data not shown). Nevertheless, the prevalence of testing FBG $\geq 1$ time per year for obese or overweight patients with additional risk factors was slightly although statistically significantly higher for practices that received incentive payments for diabetes screening compared to practices that did not receive incentives $(100.0 \%$ vs. $96.2 \%$, p $<0.001)$ (Table 4); for patients without additional risk factors, the trend toward more testing by physicians receiving incentive payments was not statistically significant.

\begin{tabular}{|c|c|c|c|c|}
\hline & \multicolumn{3}{|c|}{ Percent Testing Fasting Blood Glucose $\geq 1$ Time Per Year } \\
\hline & With additional risk factors & \multicolumn{2}{|c|}{ Without additional risk factors } \\
\hline & $\mathbf{N}$ & \% (SE) & N & $\%$ (SE) \\
\hline Overall & 501 & $96.9(0.6)$ & 440 & $80.8(1.7)$ \\
\hline Incentive payments for diabetes screening* & 487 & & 427 & $79.8(1.9)$ \\
\hline No & & $96.2(0.7)^{\mathrm{a}}$ & & $86.5(4.5)$ \\
\hline Yes & & $100.0(0.0)^{\mathrm{a}}$ & & \\
\hline
\end{tabular}

Table includes respondents who completed both the physician and practice environment questionnaire (55.5\% response rate) and physicians who utilized the screening test.

The standard error is a measure of the sampling variability in the estimate; it is a function of the population standard deviation, the sample size, and the study design.

*Few physicians reported "don't know" whether they received incentive payments for diabetes screening (N = 14 for those treating patients with additional risk factors; $\mathrm{N}=13$ for those treating patients without additional risk factors); Data include only those physicians whose practices reported on incentive payments for diabetes screening. ${ }^{\mathrm{a}} \mathrm{p}<0.001$

Table 4: Prevalence of testing FBG $\geq 1$ time/year for patients who are overweight/obese by incentive payments for diabetes screening

\section{Discussion}

This national survey suggests that PCPs are testing for diabetes and prediabetes at high frequency for their adult patients at risk, with more than $90 \%$ testing FBG in overweight and obese patients with additional risk factors, and the vast majority testing annually or more frequently. Even when treating overweight and obese adults without additional risk factors, more than $85 \%$ of PCPs report measuring FBG at least every two years.

Although fewer physicians report monitoring random blood glucose than FBG, a majority report using random blood glucose testing at least every two years. Although random blood glucose is not recommended for screening for diabetes or prediabetes, it is possible that random blood glucose is done as part of a standard laboratory panel being collected for other purposes; or it may be measured because requiring a patient to come to the doctor's office for a fasting sample is inconvenient. However, the ADA offers an HbA1c testing as an alternative to FBG or OGTT, and this may be an option when obtaining FBG or an OGTT are not feasible. In addition, the FBG is the preferred test to diagnose diabetes because it is more convenient for patients, less costly, and 
the repeat-test reproducibility is better compared to the OGTT [17]. Use of HbA1c testing was not assessed in this survey, but PCPs may wish to consider using HbA1c to screen for dysglycemia when their patient comes to the office in a non-fasting state. For monitoring of glycemic control in patients with diabetes, self-monitoring of blood glucose and HbA1c are recommended, rather than a single random blood glucose.

This study had many strengths, including surveying a nationally representative sample of PCPs in four different specialties. Limitations include lack of information on potential screening measures for diabetes or prediabetes other than FBG or RBG. Therefore, this survey could have underestimated the percentage of physicians who are screening for diabetes. Since the phrase additional risk factors were not defined for the physicians in the questionnaire, they likely included patients with diabetes in their responses to frequency of glucose testing. Thus, the distribution for frequency of testing blood glucose reported here may be shifted higher since those with diabetes would be expected to have their blood glucose tested more frequently than those without diagnosed diabetes. In addition, survey data on PCP behaviors did not obtain information regarding how these counseling or testing behaviors differed based on patient age. It is likely that internists and family physicians would be treating an older cohort of patients, in whom blood glucose screening is recommended even without additional risk factors, while OB-GYNs, whose patient population would likely be skewed towards women of childbearing age, would have more patients in whom diabetes screening would not be indicated based on age criteria alone [18]. Thus, the relatively low prevalence of glucose screening for patients without additional risk factors (54\%) in OB-GYNS compared with internists (91\%) and family physicians (77\%) may reflect screening practices of differing populations of patients. Finally, the data on screening is self-reported by physicians. However, a previous validation study suggests that physician self-report of preventive medicine behaviors and practices is reliable [19].

In this survey, PCPs reported being very likely to provide general counseling for changing diet, physical activity, or weight for patients with type 2 diabetes or a family history of diabetes; the prevalence of providing counseling was higher for these patients compared to those with unhealthy behaviors or overweight but without weight-related chronic disease. Patient perceptions of physicians' advice on weight control may differ from that reported by physicians. A study of patients with prediabetes found that only about $1 / 3$ reported receiving advice on weight control, change in diet, or physical activity [20].

Smith, et al found that even when PCPs do report high levels of weight control counseling, only 60\% reported systematically tracking/following patients with weight related chronic diseases over time to assess progress related to diet, physical activity or weight control, and only $43 \%$ reported such tracking for their lower-risk patients without weight related chronic disease [13]. Lowintensity counseling by physicians has not been shown to lead to successful weight loss, suggesting the need for additional physician training in evidence-based strategies for providing comprehensive lifestyle intervention counseling, as well as alternative modes of delivery, including referral to other health professionals or programs [21]. Unfortunately, a minority report referring their overweight patients or patients with unhealthy diet and physical activity behaviors to a health professional or program outside of their practice for evaluation and/or management. Additional results from Smith, et al indicated that even among patients with weight-related chronic disease, only $41 \%$ report often or always making such referrals, and only a small number (18\%) routinely referred patients without weight related chronic diseases for further evaluation or management [13]. Improvements in structural factors that impact practice, such as reminder or referral systems using the electronic medical record, clinician incentives for screening and management, training and reimbursement for lifestyle counseling, and access to trained interventionists may all improve the likelihood of proper provision of energy balance care [15].

Physicians are more often utilizing ADA-recommended FPG testing than random blood glucose testing in their U.S. practices. In addition, the majority are testing FPG at least annually, regardless of whether their overweight or obese patients have additional risk factors, and are providing general counseling on healthy lifestyle behaviors to their patients with type 2 diabetes or a family history of diabetes. Although these results are quite positive, it is unknown how these factors ultimately affect diabetes prevention and diabetes management. Further investigation is needed on how these practices translate to individual outcomes.

\section{Acknowledgement}

This study was supported by the National Institute of Diabetes and Digestive and Kidney Diseases (contract \# GS-10F-0381L). The findings and conclusions in this report are those of the authors and do not necessarily represent the views of the National Institute of Diabetes and Digestive and Kidney Diseases or the National Cancer Institute.

\section{References}

1. American Diabetes Association (2013) Economic Costs of Diabetes in the U.S. in 2012. Diabetes Care 36: $1033-46$.

2. Centers for Disease Control and Prevention (2011) National Diabetes Fact Sheet: National Estimates and general information on diabetes and prediabetes I the United States, Atlanta, U.S.A.

3. Knowler WC, Barrett-Connor E, Fowler SE, Hamman RF, Lachin JM, et al. (2002) Reduction in the incidence of type 2 diabetes with lifestyle intervention or metformin. N Engl J Med 346: 393-403.

4. The Surgeon General's vision for a healthy and fit nation (2010) United States Department of Health and Human Services (DHHS), Rockville, MD, USA.

5. Flegal KM, Carroll MD, Kit BK, Ogden CL (2012) Prevalence of obesity and trends in the distribution of body mass index among US adults, 1999-2010. JAMA 307: 491-7. 
6. LeBlanc E, O’Connor E, Whitlock EP, Patnode C, Kapka T (2011) Screening for and Management of Obesity and Overweight in Adults, U.S. Preventive Services Task Force Evidence Syntheses, formerly Systematic Evidence Reviews, Agency for Healthcare Research and Quality (AHRQ), Rockville, Maryland, USA.

7. Kreuter MW, Chheda SG, Bull FC (2000) How does physician advice influence patient behavior? Evidence for a priming effect. Arch Fam Med 9: 426-33.

8. Petrella RJ, Lattanzio CN (2002) Does counseling help patients get active? Systematic review of the literature. Can Fam Phys 48: $72-80$.

9. Calfas KJ, Long BJ, Sallis JF, Wooten WJ, Pratt M, et al. (1996) A controlled trial of physician counseling to promote the adoption of physical activity. Prev Med 25: 225-33.

10. Galuska DA, Will JC, Serdula MK, Ford ES (1999) Are health care professionals advising obese patients to lose weight? JAMA 282: 1576-8.

11. Tsai AG, Wadden TA (2009) Treatment of obesity in primary care practice in the United States: a systematic review. J Gen Intern Med 24: 1073-9.

12. Jensen MD, Ryan DH, Donato KA, Apovian CM, Ard JD, et al. (2014) AHA/ACC/TOS guideline for the management of overweight and obesity in adults: a report of the American College of Cardiology/ American Heart Association Task Force on Practice Guidelines and The Obesity Society. Obesity 22: 41-410.

13. Smith AW, Borowski LA, Liu B, Galuska DA, Signore C, et al. (2011) U.S. primary care physicians' diet-, physical activity-, and weight-related care of adult patients. Am J Prev Med 41: 33-42.

14. American Diabetes Association (2013) Standard of Medical Care-2013. Diabetes Care 36: S11-S66.

15. Klabunde CN, Clauser SB, Liu B, Pronk NP, Ballard-Barbash R, et al. (2014) Organization of primary care practice for providing energy balance care. Am J Health Promot 28: e67-80.

16. Wolter KM (2007) Introduction to Variance Estimation. Springer-Verlag New York, USA.

17. International Expert Committee (2009) International Expert Committee report on the role of the A1C assay in the diagnosis of diabetes. Diabetes Care 32: 1327-34.

18. IMS Health (2014) National Disease and Therapeutic Index, Specialty Profiles, USA.

19. Yeazel MW, Lindstrom Bremer KM, Center BA (2006) A validated tool for gaining insight into clinicians' preventive medicine behaviors and beliefs: the preventive medicine attitudes and activities questionnaire (PMAAQ). Prev Med 43: 86-91.

20. Geiss LS, James C, Gregg EW, Albright A, Williamson DF, et al. (2010) Diabetes risk reduction behaviors among U.S. adults with prediabetes. Am J Prev Med 38: 403-9.

21. Carvajal R, Wadden TA, Tsai AG, Peck K, Moran CH (2013) Managing obesity in primary care practice: a narrative review. Ann N Y Acad Sci 1281: $191-206$.

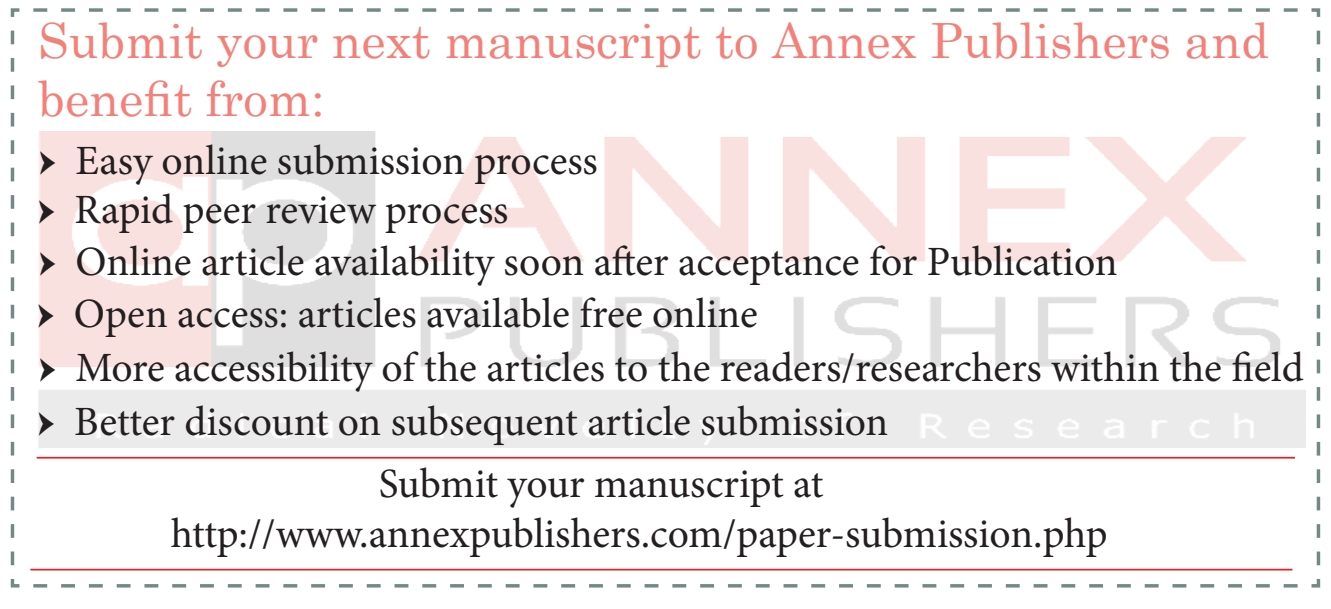

